\title{
Bidirectional erosion of cartilage in the rheumatoid knee joint
}

\author{
MICHAEL BROMLEY, ${ }^{1}$ HARVEY BERTFIELD,${ }^{2}$ JOHN M EVANSON, \\ AND DAVID E WOOLLEY
}

From the ${ }^{1}$ Department of Medicine, University Hospital of South Manchester, Manchester M20 8LR; and the $e_{\odot}$ ${ }^{2}$ Department of Orthopaedics, Wythenshawe Hospital, Manchester M23 9LT

SUMMARY Specimens of cartilage with contiguous bone and overlying synovial pannus werę obtained from 22 rheumatoid knee joints and examined histologically using specific histochemicat staining techniques. All showed significant erosions of cartilage by synovial cells, but seve $\vec{p}$ specimens also showed substantial cartilage erosion by cells from the subchondral bone region $\rightarrow$ This bidirectional attack on rheumatoid knee cartilage did not represent an 'underpinning' of cartilage by synovial pannus, as judged by serial sectioning and the identification of specific cells?. Whereas cartilage-pannus junctions had mainly macrophagic or fibroblastic cells, cartilage-bone lesions were usually characterised by chondroclasts and blood vessels. Lymphocytes werf generally absent from all sites of cartilage erosion. The bidirectional attack on articular kne cartilage suggests that changes have occurred within the cartilage that make it vulnerable to. cellular invasion and erosion. Such changes might reflect a deficiency in 'anti-invasion factors' the exposure of hidden epitopes and subsequent immunogenicity, or a combination of bothe

Key words: histopathology, inflammation, synovial cells, chondroclasts.

A basic feature of joint damage in rheumatoid arthritis (RA) is the progressive erosion of articular cartilage and contiguous bone, which eventually results in loss of normal joint function and is generally irreversible. Cartilage degradation has been shown by numerous histological studies to be brought about by the invasive hypertrophic synovial pannus tissue,${ }^{1-4}$ by chondrocytes, ${ }^{5}$ or from the subchondral bone region. ${ }^{26}$ During our studies on the identification of cell types at sites of cartilage erosion in $\mathrm{RA}^{4}$ we became aware that some cartilage specimens were degraded not only by the overlying synovial pannus tissue but also by cellular infiltrations from subchondral, probably bonederived cells. Although other reports have indicated that cartilage erosion may result from either pannus or bone-derived tissue, and the process of 'underpinning' cartilage by synovial tissue has been well described in small joints, ${ }^{6}$ the cell types associated with bidirectional cartilage erosion in rheumatoid

Accepted for publication 11 March 1985.

Correspondence to Dr D E Woolley, Department of Medicine, University Hospital of South Manchester, West Didsbury, Manchester M20 8LR. knee specimens have not been previously describe We report here the identification of specific celt $\$$ found at sites of cartilage erosion, and show the susceptibility of rheumatoid knee cartilage to bidire tional attack from both synovial pannus and boner derived cells.

\section{Materials and methods}

Cartilage-pannus junctions with attached bone were dissected out from tissue removed during arthro plasty of the knees of 22 seropositive patients wi classical rheumatoid arthritis. Each specimen was: fixed for two hours in $1 \%$ formaldehyde and $0.25 \%$ glutaraldehyde in $0.1 \mathrm{M}$ sodium cacodylate buffar (pH 7.4) and rinsed in $0.15 \mathrm{M}$ sodium cacodylafo (pH 7.4) before acetone dehydration. The specis mens were infiltrated overnight in JB-4 solution $\AA$ (Polysciences Ltd, Northampton) and final embedded in the complete JB-4 mixture (20 nit A/0.15 g initiator $+0.7 \mathrm{ml} \mathrm{B}$ ). All procedures wete carried out at $4^{\circ} \mathrm{C}$. Tissue sections $2.5 \mu \mathrm{m}$ thick were cut on an LKB Historange microtome, floated on water, and dried down on glass coverslips at $30^{\circ} \mathrm{C}_{\mathbb{C}}^{\circ}$ 


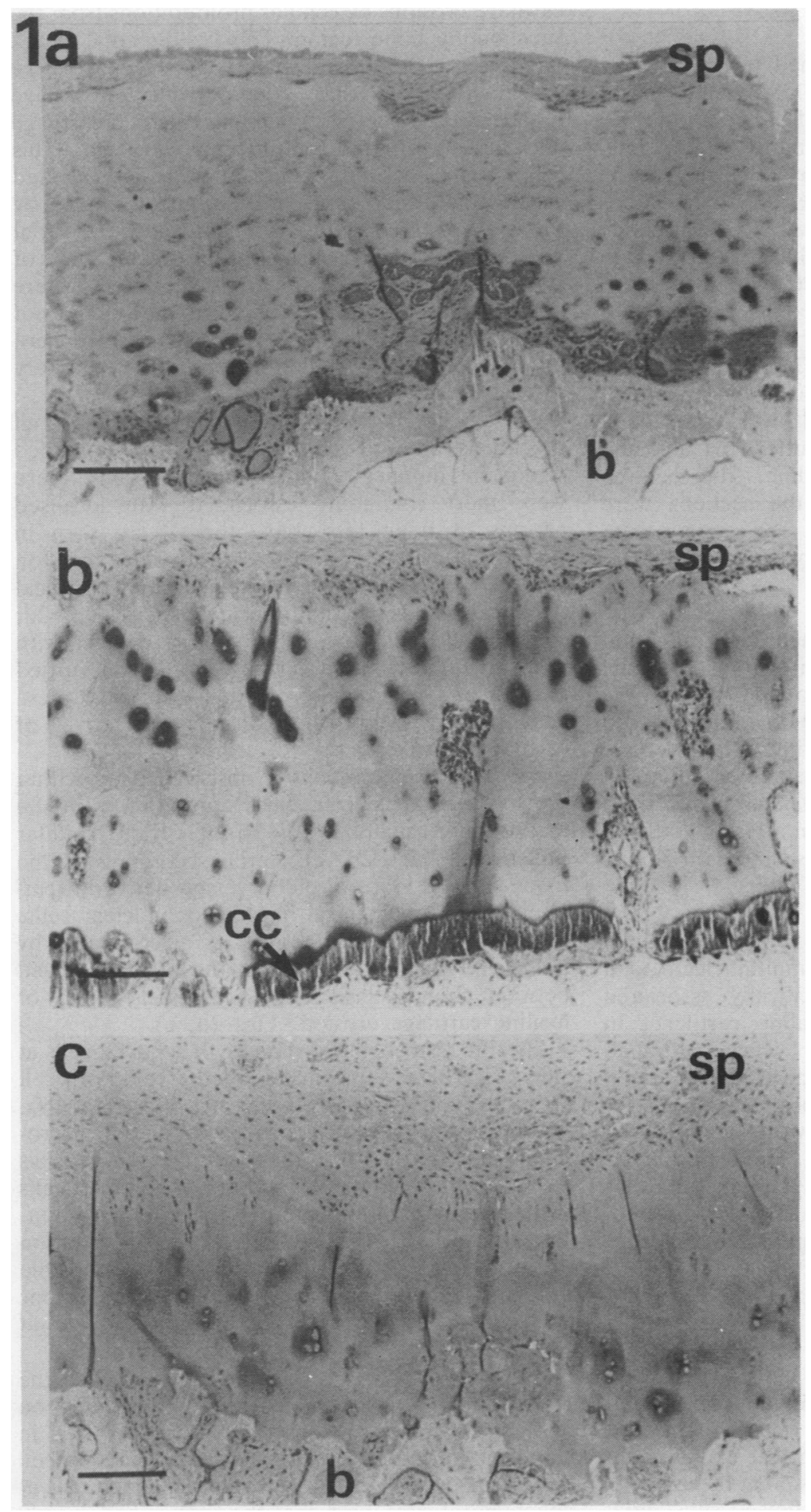

Fig. 1 Bidirectional attack on rheumatoid knee cartilage by synovial pannus and subchondral, bone-derived cells.

(a) Photomicrograph showing cartilage erosion by synovial pannus (sp) and bone (b)-derived tissues. Note prominent blood vessels of subchondral cellular infiltration. Tissue section stained with methylene blue-azure II. Bar $=200 \mu \mathrm{m}$.

(b) Photomicrograph of cartilage with overlying, erosive synovial pannus (sp) and pockets of cells within the cartilage derived from bone tissue which has breached the calcified cartilage (cc). Tissue section stained with methylene blue-azure II. Bar $=200 \mu \mathrm{m}$. (c) Photomicrograph showing cartilage erosion by overlying synovial pannus (sp) and subchondral bone-derived cells. Note the removal of calcified cartilage and supporting bone (b). Tissue section stained with methylene blue-azure II. Bar $=\mathbf{2 0 0}$ um. 
EN Z Y ME HISTOCHEMISTRY

Acid phosphatase $(A P)^{7}$

The incubation medium contained $0.3 \mathrm{ml}$ hexazotised pararosaniline in $10 \mathrm{ml} 0.1 \mathrm{M}$ acetate buffer (pH 5.0), $0 \cdot 1 \mathrm{ml} 10 \%(\mathrm{w} / \mathrm{v}) \mathrm{MnCl}_{2}$, and $5 \mathrm{mg}$ naphthol AS B1 phosphate (Sigma, Poole) in $1 \mathrm{ml}$ ethylene glycol monomethyl ether (EGMME). The medium was filtered before use, and the sections were incubated for three hours at $37^{\circ} \mathrm{C}$. The tissue sections were counterstained with $0.25 \%$ azure II in $0.25 \%$ borax and $0.25 \%$ methylene blue, rinsed in water, blow dried, and mounted.

\section{Naphthyl acetate esterase $(N A E)^{8}$}

The incubation medium contained $10 \mathrm{mg} \alpha$-naphthyl acetate (Sigma) in $0.5 \mathrm{ml}$ EGMME which was added to $9.5 \mathrm{ml} 0.067 \mathrm{M}$ phosphate buffer $(\mathrm{pH} \mathrm{6.3)}$ and $0.05 \mathrm{ml}$ hexazotised pararosaniline. The medium was filtered before use, and the sections were incubated for two hours at $37^{\circ} \mathrm{C}$. The sections were counterstained as described above.

\section{Chloroacetate esterase $(C A E)^{8}$}

The incubation medium contained $2 \mathrm{mg}$ naphthol AS-D chloroacetate (Sigma) in $0.5 \mathrm{ml}$ dimethyl formamide which was added to $9.5 \mathrm{ml} 0.067 \mathrm{M}$ phosphate buffer ( $\mathrm{pH} \mathrm{7.4)}$ and $0.05 \mathrm{ml}$ hexazotised new fuchsin. The medium was filtered before use, and the sections were counterstained as described above. Photomicrographs were taken on a Vickers M41 photoplan microscope or on a Nachet NS 400 for Nomarski interference microscopy, with Kodak Panatomic $X$ film and a green filter.

\section{Cell identification}

Chondroclasts were identified as multinucleate, acid phosphatase-positive cells, specifically associated with either mineralised or hyaline cartilage, in contradistinction to osteoclasts which, although having similar morphological and histochemical properties, were specifically associated with mineralised bone. Macrophagic cells were identified by their intense staining with NAE. Some fibroblasts were weakly positive for NAE staining but were usually identified by their typical bipolar morphology. Polymorphonuclear neutrophils (PMNs) were recognised by their positive reaction for CAE and their characteristic nuclear morphology.

\section{Results}

Specimens of cartilage with contiguous bone and overlying synovial pannus were obtained from 22 rheumatoid knee joints. Histological examination consistently showed cartilage erosion at the synovial interface, but seven specimens showed substantial cartilage erosions by cellular proliferations from the subchondral bone region. This bidirectional attact on cartilage is illustrated in Fig. 1 where three: specimens show that bone-derived cells have breached the bone end plate and calcified cartilage and have infiltrated the hyaline cartilage. This cellular invasion of the bone end plate and calcifie cartilage did not represent an underpinning b synovial pannus tissue, as confirmed by seriad sectioning and the absence of histological features of synovial pannus tissue. In a few specimens wher underpinning by pannus was observed this did not extend to the subchondral regions described herf but was confined to limited regions at the peripheres of the bone.

Closer examination of the subchondral sites of at+ specimens showed that the majority containe 5 significant numbers of multinucleated cells; these were most commonly associated with localise $\$$ regions of bone loss, but others were seen if significant numbers at sites of cartilage erosion (Fig. 2). Chondroclasts were identified as aci\& phosphatase-positive, multinucleated cells (Figs. 2d e) which were always in very close contact wito calcified or uncalcified cartilage, and their ruffled borders of cytoplasmic projections suggested these cells were actively engaged in the removal 50 of cartilage matrix.

Blood vessels were often observed deep within the hyaline cartilage in close apposition with the matrix and usually at the front of the cellulap infiltration (Figs $2 b, c)$. Serial sectioning of the tissue showed loops of blood vessels derived exclu sively from subchondral bone. Mononuclear cells some of which were identified as macrophages be NAE and AP staining, were always intersperse between chondroclasts and blood vessels at sites of hyaline cartilage erosion (Figs $2 \mathrm{~d}$, e).

Specific histochemical staining of synovial cells a sites of cartilage erosion identified a variety of celf types including macrophages, fibroblasts, PMNs $\frac{0}{2}$ and mast cells. Most specimens contained macrophages and fibroblasts as the majority cell type (Figs 3a, b, d) but in others PMNs (Fig. 3c) and mast cello were predominant at the cartilage-pannus junction Usually each specimen showed a mixed population of cells (Figs 3a, e), but in most cases it was possible्, to identify one predominant type. Several specimen showed local accumulations of different cell types af sites along a single junction.

There was no apparent correlation between the types of cell found at the cartilage-pannus junction and the extent of subchondral cartilage erosion in the same specimen. The major differences in cello types found at the cartilage-pannus junction and a subchondral sites were that the former had mainls? 


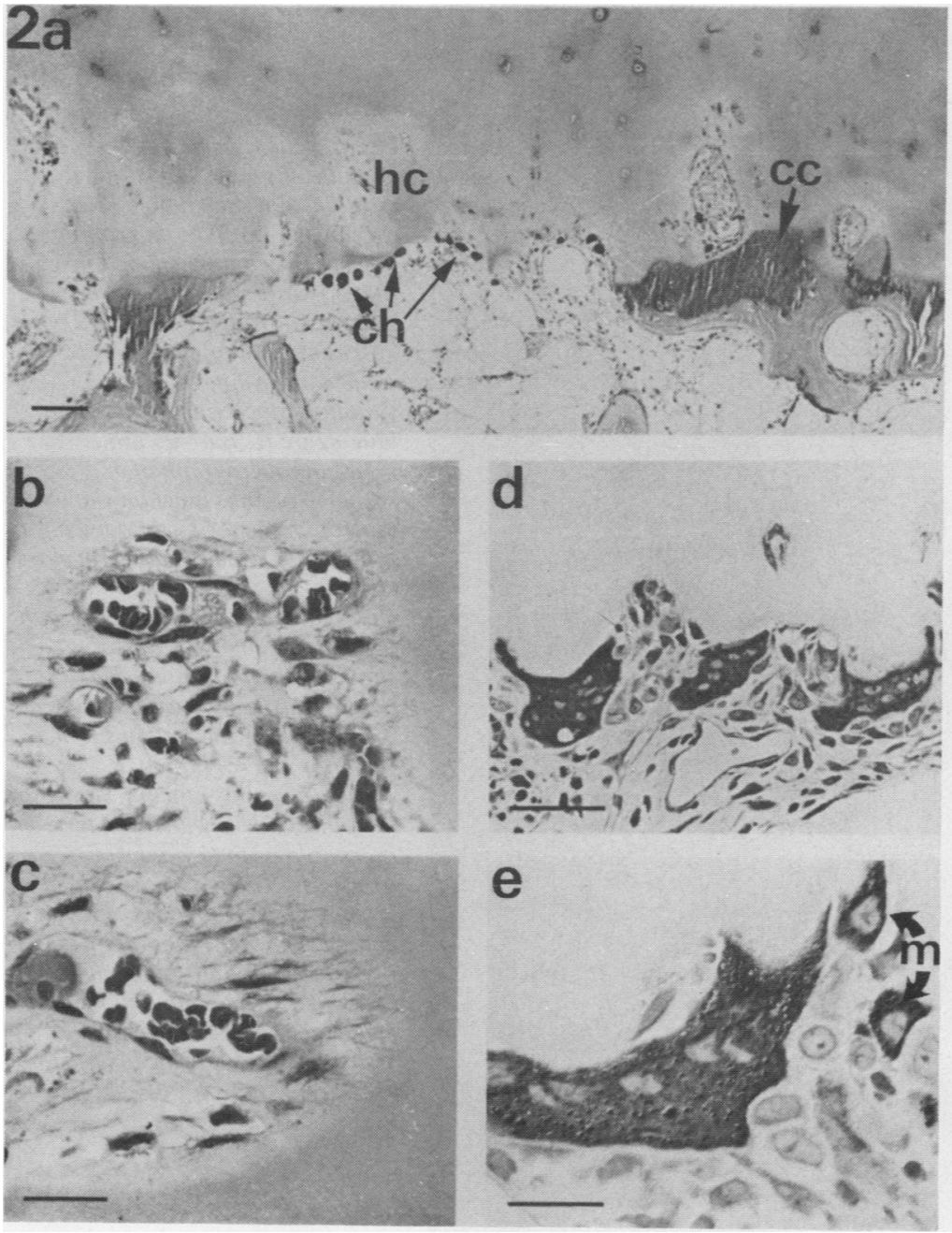

Fig. 2 Subchondral cartilage erosion in rheumatoid knee joints by bone-derived cells.

(a) Photomicrograph showing loss of bone, calcified (cc) and hyaline cartilage (hc). Tissue section stained for acid phosphatase to show chondroclastic cells (ch) and counterstained with methylene blue-azure II. Bar $=100 \mu \mathrm{m}$. (b and c) Photomicrographs of blood vessels penetrating hyaline cartilage and in close apposition to the matrix. Tissue sections stained with methylene blue-azure II. Bar $=20 \mu \mathrm{m}$. (d) Photomicrograph of subchondral cartilage erosion by chondroclasts. These multinucleated cells consistently showed intimate contact with cartilage. Tissue section stained for acid phosphatase and methylene blue-azure II. Bar $=50 \mu \mathrm{m}$. (e) Nomarski interference micrograph of a chondroclast and two macrophagic cells $(m)$ stained for acid phosphatase. Bar $=20 \mu \mathrm{m}$.

macrophagic or fibroblastic cells, whereas the latter had blood vessels and chondroclasts. Multinucleated osteoclasts and chondroclasts were unique to subchondral erosion sites and were never observed at the cartilage-pannus junction.

\section{Discussion}

The 22 rheumatoid knee specimens examined here were originally obtained for examination of the cartilage-pannus junction with the aims of identifying the cells at sites of cartilage erosion. During the study it was noted that a majority of the specimens also showed significant depletion of mineralised bone and calcified cartilage associated with the presence of subchondral multinucleated cells. ${ }^{169}$
Moreover, seven specimens showed erosion of the bone end plate and calcified cartilage with subchondral, cellular infiltrations penetrating and eroding the hyaline cartilage. This bidirectional attack on rheumatoid knee cartilage did not reflect an 'underpinning' by proliferating synovial tissue as previously reported for smaller metacarpophalangeal (MCP) joints. ${ }^{6}$ Indeed, our preliminary comparative studies on knee and MCP joint histology have suggested quite different patterns of erosion, with 'underpinning' ${ }^{10}$ and detachment ${ }^{11}$ of cartilage being characteristic features of small joint pathology.

Cartilage degradation was always most marked where cells of the synovial pannus were in direct contact with cartilage, a junctional site where the 


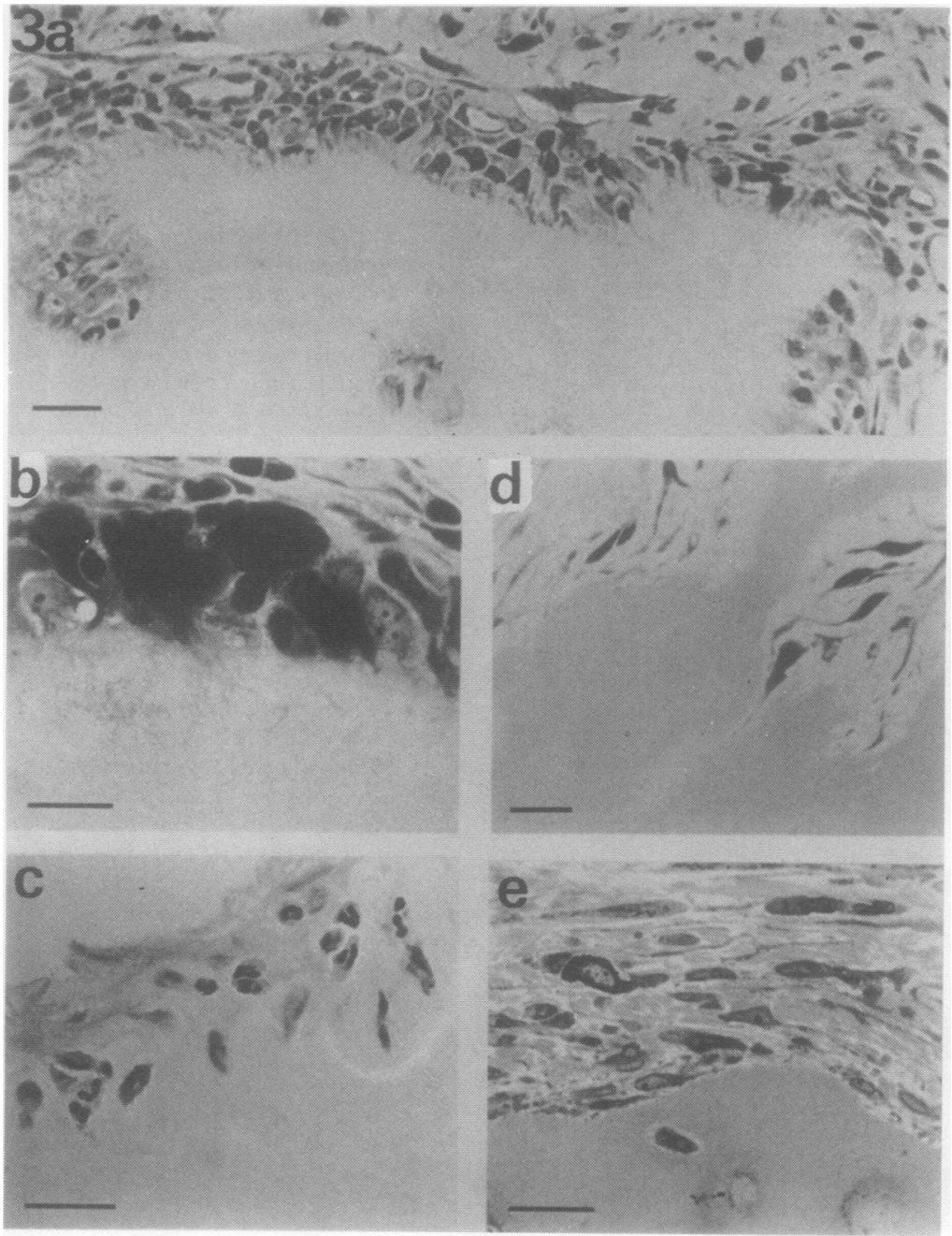

Fig. 3 Identification of synoviat pannus cells at sites of cartilage erosion from rheumatoid knee specimens. (a) Photomicrograph of a cartilage-pannus junction stained for $\alpha$-naphthyl acetate esterase showing different cell types at sites of erosion. Note darkly stained macrophages.

Counterstained with methylene blue-azure II. Bar $=25 \mu \mathrm{m}$. (b) Photomicrograph of a cartilage-pannus junction showing macrophages positively stained for $\alpha$-naphthyl acetate esterase in close contact with the cartilage matrix. Bar $=10 \mu \mathrm{m}$. (c) Photomicrographo of a cartilage-pannus junction showing polymorphonuclear neutrophils stained with methylene blue-azure II. Bar $=20 \mu \mathrm{m}$. (d) Photomicrograph of a cartilage-pannus junction showing fibroblastic cells with bipolar morphology and cytoplasmic ov processes. Tissue section stained with methylene blue-azure II. Bar $=10 \mu \mathrm{m}$. (e) Photomicrograph of cartilage-pannus junction showing a mixed population of synovial cells. Tissue section stained with methylene blue-azure II. $B$ ar $=20$ um.

presence of cartilage-degrading enzymes such as collagenase $^{12}$ and elastase $^{13}$ has been shown by immunolocalisation techniques. Specific histochemical staining and ultrastructural observations have identified the cell types at cartilage-pannus junctions, and although macrophages and fibroblasts (synovial A and B cells) were commonly observed as the majority cell types, mast cells, PMNs, dendritic, and plasma cells predominated in some specimens. ${ }^{4}$ Moreover, local accumulations of two or more different cell types were observed in some junctional specimens. These findings indicated that the cellular composition at synovial sites of cartilage erosion is very variable, an observation most easily explained by cellular turnover or interchange, or both. ${ }^{4}$
Subchondral erosions of calcified and hyaline cartilage were observed in regions remote from the cartilage-pannus junction and were commonly associated with chondroclasts, blood vessels, an mononuclear cells such as macrophages. Interest ingly, in the normal development of the tibiab epiphyseal growth plate Schenk ${ }^{14}$ has shown that hyaline cartilage resorption was associated with capillary ingrowth, whereas mineralised cartilage was removed by chondroclasts. Similar observations are reported here for the subchondral erosion of 'rheumatoid' cartilage, except that the chondroclasts appeared capable of resorbing both mineralised and hyaline cartilage as judged by ultrastructural evidence of ruffled borders, phagocytosis of collagend fibrils, cytoplasmic digestive vacuoles, and lyso $\frac{\mathrm{D}}{\circ}$ 
somal bodies containing acid phosphatase. ${ }^{9}$ Although morphologically and histochemically similar to osteoclasts, the chondroclasts described here were never seen at cartilage-pannus junctions and had staining properties very different from synovial giant cells which were rarely found close to cartilage. Similarly, whereas blood vessels in subchondral erosions were frequently seen in juxtaposition to hyaline cartilage, they were seldom seen at cartilagepannus junctions. Lymphocytes were generally absent from all sites of cartilage erosion and although observed in variable numbers in synovial tissue remote from the junction they were seldom seen in subchondral locations. Our studies therefore indicate that the two erosive fronts, synovial and subchondral, are characterised by different cell types, usually with far fewer inflammatory cells at the latter sites. Since we have not examined cartilage specimens which lacked overlying synovial pannus tissue, we do not know whether subchondral cartilage degradation precedes or follows that resulting from pannus.

Kuettner and colleagues ${ }^{15}$ have shown that cartilage is generally resistant to invasion by a variety of tumour cells and blood vessels, a property explained by the presence of 'anti-invasion factors' (AIF). Such inhibitory preparations derived from cartilage are known to prevent both tumour cell invasion ${ }^{16}$ and osteoclastic activity, ${ }^{17}$ and also possess anticollagenase activity. ${ }^{18}$ The clear invasion of cartilage shown here for synovial and presumably bonederived cells might suggest that 'rheumatoid' cartilage is deficient in AIF. Alternatively, the immunogenicity of cartilage collagen and/or proteoglycans which has been reported in rheumatoid arthritis ${ }^{19-21}$ might be responsible for the cartilage erosion at the two locations. Accordingly, bidirectional attack on articular knee cartilage could reflect either changes occurring within the cartilage making it vulnerable to cellular invasion and erosion, or the exposure of hidden epitopes and subsequent immunogenicity, or a combination of both. In favour of the former explanation is the observation in some specimens that inflammatory cells were absent or sparse at sites of subchondral cartilage degradation. In any event, these observations point to a need for further detailed biochemical analyses of 'rheumatoid' cartilage to define its primary or secondary role in the rheumatoid process.

We thank Mr H Williams and Mr W Fisher, Consultant Orthopaedic Surgeons, for the supply of specimens and Mrs K Hale and Mrs M Williamson for the preparation of the typescript. This work was supported by the Arthritis and Rheumatism Council.

\section{References}

1 Gardner D L. Pathology of rheumatoid arthritis. In: Scott J T. ed. Copeman's textbook of rheumatoid diseases. 5th ed. Edinburgh: Churchill Livingstone, 1978; 273-317.

2 Fassbender H G. Pathology of rheumatic diseases. Berlin: Springer, 1975: 109-11.

3 Kobayashi I, Ziff $M$. Electron microscopic studies of the cartilage-pannus junction in rheumatoid arthritis. Arthritis Rheum 1975; 18: 475-83.

4 Bromley M, Woolley D E. Histopathology of the rheumatoid lesion: identification of cell types at sites of cartilage erosion. Arthritis Rheum 1984; 27: 857-63.

5 Mitchell N S, Shephard N. Changes in proteoglycan and collagen in cartilage in rheumatoid arthritis. J Bone Joint Surg 1978; 60A: $349-54$.

6 Uhlinger E. Bone changes in rheumatoid arthritis and their pathogenesis. In: Muller W, Harwerth H G, Fehr K, eds. Rheumatoid arthritis: pathogenic mechanisms and consequences in therapeutics. London: Academic Press, 1971: 25-36.

7 Evans R A, Dunstan C R. Baylink D J. Histochemical identification of osteoclasts in undecalcified sections of human bone. Mineral Electrolyte Metab 1979; 2: 179-85.

8 Yam L T, Li C Y. Crosby W H. Cytochemical identification of monocytes and granulocytes. Am J Clin Pathol 1971; 55: 283-90.

9 Bromley M, Woolley D E. Chondroclasts and osteoclasts at subchondral sites of erosion in the rheumatoid joint. Arthritis Rheum 1984; 27: 968-75.

10 Wyllie J C. Histopathology of the subchondral bone lesion in rheumatoid arthritis. J Rheumatol 1983; 10: 26-8.

11 Barrie $\mathrm{H} \mathrm{J}$. Histologic changes in rheumatoid disease of the metacarpal and metatarsal heads as seen in surgical material. $J$ Rheumatol 1981; 8: 246-57.

12 Woolley D E, Crossley M J, Evanson J M. Collagenase at sites of cartilage erosion in the rheumatoid joint. Arthritis Rheum 1977; 20: 1231-9.

13 Menninger M, Putzier R, Mohr W. Wessinghage D, Tillman K. Granulocyte elastase at the site of cartilage erosion by rheumatoid synovial tissue. Z Rheumatol 1980; 39: 145-56.

14 Schenk R K, Spiro D, Wiener J. Cartilage resorption in the tibial epiphyseal plate of growing rats. J Cell Biol 1967; 34: 275-91.

15 Kuettner K E, Pauli B U, Soble L. Morphological studies on the resistance of cartilage to invasion by osteosarcoma cells in vitro and in vivo. Cancer Res 1978: 38: 277-87.

16 Pauli B U, Memoli V A, Kuettner K E. Regulation of tumour invasion by cartilage-derived anti-invasion factor in vitro. $J$ Natl Cancer Inst 1981; 67: 65-73.

17 Horton J E, Wezeman F N, Kuettner K E. Inhibition of bone resorption in vitro by a cartilage-derived anti-collagenase factor. Science 1978; 199: 1342-5.

18 Pauli B U, Kuettner K E. The regulation of invasion by a cartilage-derived anti-invasion factor. In: Liotta L A. Hart I R. eds. Tumour invasion and metastasis. Boston: Nijhoff, 1982: 267-90.

19 Trentham D E, Dynesius R A, Rocklin R E, David J R. Cellular sensitivity to collagen in rheumatoid arthritis. $N$ Engl $J$ Med 1977; 299: 327-32.

20 Hanauske-Abel H M, Pontz B F, Schorlemmer H U. Cartilage specific collagen activates macrophages and the alternative pathway of complement: evidence for an immunopathogenic concept of rheumatoid arthritis. Ann Rheum Dis 1982; 41: 168-76.

21 Champion B R. Sell S, Poole A R. Immunity to homologous collagens and cartilage proteoglycans in rabbits. Immunology 1983: 48: 606-16. 